\title{
Is signet-ring cell carcinoma a specific entity among gastric cancers?
}

\author{
Thibault Voron $^{1}$ - Mathieu Messager,11,12 - Alain Duhamel ${ }^{3,11,13} \cdot$ Jérémie Lefevre $^{1,10}$ • \\ Jean-Yves Mabrut ${ }^{4} \cdot$ Diane Goere $^{5} \cdot$ Bernard Meunier $^{6} \cdot$ Cecile Brigand $^{7}$. \\ Antoine Hamy $^{8} \cdot$ Olivier Glehen $^{9}$ Christophe Mariette ${ }^{2,11,12,13} \cdot$ François Paye $^{1,10}$
}

Received: 7 May 2015/Accepted: 2 November 2015/Published online: 25 November 2015

(c) The International Gastric Cancer Association and The Japanese Gastric Cancer Association 2015

\begin{abstract}
Background The prognosis and chemoresistance of signet-ring cell (SRC) gastric adenocarcinoma have been reported and debated, and the utility of perioperative chemotherapy for such a tumor has been questioned. This study was performed to assess the impact of the SRC type on survival following resection of gastric adenocarcinoma, and to assess whether the prognostic factors (including perioperative chemotherapy) for non-SRC adenocarcinoma differed from those for SRC adenocarcinoma.

Methods 1799 cases of adenocarcinoma that were consecutively treated from 1997 to 2010 in 19 French centers by subtotal or total gastrectomy were included in a
\end{abstract}

On behalf of the FREGAT (French Eso-GAstric Tumours) working group-FRENCH (Fédération de Recherche en Chirurgie).

Electronic supplementary material The online version of this article (doi:10.1007/s10120-015-0564-2) contains supplementary material, which is available to authorized users.

François Paye

francois.paye@aphp.fr

1 Department of Digestive Surgery, Saint Antoine Hospital, 184 rue du Faubourg Saint Antoine, 75012 Paris, France

2 Department of Digestive and Oncological Surgery, Claude Huriez University Hospital, Lille, France

3 Department of Biostatistics, University Hospital, Lille, France

4 Department of Digestive Surgery, Lyon University Hospital, Lyon, France

5 Department of Digestive Surgery, Gustave Roussy Institute Villejuif, Villejuif, France

6 Department of Digestive Surgery, Rennes University Hospital, Rennes, France retrospective study. A D2 lymphadenectomy was performed for antropyloric tumors, and a modified D2 for upper tumors. SRC adenocarcinoma was diagnosed based on the presence of isolated carcinoma cells containing mucin.

Results A total gastrectomy was performed in 979 (54.4\%) patients. SRC adenocarcinoma was diagnosed in $899(50 \%)$ patients. Patients with an SRC tumor were more frequently female, younger, and malnourished, had lower ASA scores, and had larger tumors than non-SRC patients. Median survival in patients with non-SRC carcinoma was 51 months, as compared to 26 months in patients with SRC carcinoma $(p<0.001)$. At multivariate analysis, SRC type remained an independent adverse prognostic factor $(H R=1.182)$. Factors that were prognostic in the SRC subgroup but not in the non-SRC subgroup were age $>60$ years, linitis, and involvement of adjacent organs. In contrast to non-SRC tumors, pre- and postoperative chemotherapy did not significantly impact on survival following resection of SRC adenocarcinoma.

7 Department of Digestive Surgery, Strasbourg University

Hospital, Strasbourg, France

8 Department of Digestive Surgery, Angers University

Hospital, Angers, France

9 Department of Digestive Surgery, Lyon Sud University Hospital, Lyon, France

10 UPMC, Paris 6, France

11 North of France University, Lille, France

12 Inserm UMR837, Team 5 "Mucines Epithelial Differentiation and Carcinogenesis", JPARC, Lille, France

13 SIRIC OncoLille, Lille, France 
Conclusion In comparison to non-SRC adenocarcinoma, the SRC type has a worse prognosis, different prognostic factors, and is only poorly sensitive to perioperative chemotherapy. Non-SRC and SRC adenocarcinomas should be considered different entities in future therapeutic trials.

Keywords Gastric adenocarcinoma - Signet-ring cell · Chemotherapy $\cdot$ Surgery $\cdot$ Prognosis

\section{Introduction}

With an estimated 988,000 new cases in 2008, gastric cancer is the fifth most frequently diagnosed cancer and the third leading cause of death from cancer in the world [1]. Although the global incidence of gastric adenocarcinoma has declined in the last few years, the incidence of the signet-ring cell (SRC) type increased in the USA between 1973 and 2000 from 0.1 to 1.4 cases per 100,000 persons [2], and represents $3.5 \%$ to $45.4 \%$ of gastric carcinoma in recent publications [3-12]. According to the World Health Organization (WHO) classification, SRC carcinoma is an adenocarcinoma in which more than $50 \%$ of the tumor consists of isolated or small groups of malignant cells containing intracytoplasmic mucins [13]. This type has also been classified as the "diffuse type" (by Lauren [14]), "infiltrative type" (by Ming [15]), and "undifferentiated type" (by Nakamura [16]) of adenocarcinoma, and as "high-grade" adenocarcinoma by the UICC.

The prognosis of SRC adenocarcinoma is debated and may depend on the stage of the cancer. For early gastric cancer (described by the Japanese Endoscopy Society as gastric cancer that does not extend beyond the submucosa, whatever the lymph node status [17]), the prognosis of the SRC type has been reported to be better than that of non-SRC adenocarcinoma in four recent studies [7, 12, 18, 19], but this could be biased by the tendency of patients with SRC to be younger [20]. For advanced gastric cancer, the clinicopathological characteristics and prognosis are again controversial. While some studies have shown a better prognosis for the SRC type [12, 21], other studies have reported either a poorer prognosis of this histological type $[3,5,10,22]$ or no statistically significant difference in overall survival between patients with SRC and non-SRC tumors [4, 7, 8, 11] throughout the whole population studied or when adjustments were made to account for tumor stage [23].

Moreover, a few retrospective studies have indicated that SRC gastric adenocarcinoma may be more chemoresistant, and therefore may not respond to current therapeutic approaches available for gastric cancer in Europe (based on perioperative chemotherapy (CT) with cisplatinfluorouracil with or without epirubicin) according to two randomized trials [24, 25], and in the USA (based on postoperative adjuvant chemoradiotherapy) [26]. These distinct epidemiologies, prognoses, and responses to chemotherapy of the SRC and non-SRC types suggest that each histological type should be considered an independent disease with its own specific prognostic factors and efficient therapeutic strategies.

In the study reported in the present paper, we aimed to assess the impact of the SRC type on survival following resection of gastric adenocarcinoma, and to assess whether the prognostic factors for SRC (including perioperative chemotherapy) and non-SRC adenocarcinoma differ.

\section{Methods}

\section{Patients}

The FREGAT multicentric database gathered 3010 patients from 19 participating surgical centers who were consecutively operated on for gastric or junctional adenocarcinoma between January 1997 and March 2010. Among them, 1799 fulfilled the following inclusion criteria: the gastric adenocarcinoma did not involve the gastroesophageal junction, it was considered resectable on preoperative assessment, and it was treated by either subtotal or total gastrectomy.

\section{Preoperative investigations}

In all centers, preoperative assessment included a complete medical history, physical examination, upper gastrointestinal endoscopy with biopsies, and abdominopelvic and chest computed tomographic scans. Endoscopic ultrasound and positron emission tomography (PET) were performed when indicated according to the French National Guidelines [27]. The suitability of patients for gastrectomy, with or without perioperative chemotherapy, was considered in multidisciplinary weekly meetings of surgeons, oncologists, pathologists, and radiologists. Linitis was defined macroscopically as partial or complete thickening and rigidity of the gastric wall observed on both preoperative endoscopy and intraoperative exploration. Preoperative malnutrition was defined as a weight loss exceeding $10 \%$ of the baseline weight in the last six months. The American Society of Anesthesiologists (ASA) score was used to stratify patients according to their perioperative risk. It was assigned either in the preoperative period or at the time of surgery by the anesthesiologist according to the following guidelines: ASA 1, normal healthy patient; ASA 2, patient with mild systemic disease; ASA 3, patient with severe systemic disease; ASA 4, patient with severe systemic disease - a constant threat to life. 


\section{Perioperative treatment}

According to reported prospective trials [24, 25], perioperative CT using cisplatin and fluorouracil with/without epirubicin is recommended for operable gastric or lower esophageal adenocarcinoma by the French Guidelines [27]. The preoperative and postoperative $\mathrm{CT}$ regimens used since 2005 have varied among participating French centers, and have always included a bitherapy utilizing fluorouracil with cisplatin or oxaliplatin. In some of them, epirubicin or taxotere has also been included. Prior to 2005, upfront surgical resection was performed routinely for gastric adenocarcinoma that was deemed resectable, and postoperative CT (FOLFOX or 5-FU/cisplatin) or radioCT was considered on a case-by-case basis, taking the histological characteristics of the resected tumor and the patient's status into account. Preoperative CT was defined here as at least one cycle of preoperative $\mathrm{CT}$, and was considered in this study on an intention-to-treat basis, whatever the number of cycles of CT performed pre- and postoperatively. Postoperative CT was defined here as postoperative CT carried out in patients who had not received previous neoadjuvant chemotherapy, whatever the $\mathrm{CT}$ regimen and number of cycles.

\section{Surgical technique}

Surgery was performed 4-8 weeks after the end of the neoadjuvant chemotherapy (when administered) and 2-4 weeks after referral for patients with upfront resection.

At laparotomy, a surgical exploration of the peritoneal cavity was performed to search for liver metastasis and peritoneal carcinomatosis. The presence of ascites or localized resectable carcinomatosis was also recorded. A subtotal gastrectomy was an option for pyloric and antral tumors, providing a margin of at least $6 \mathrm{~cm}$ between the proximal resection line and the superior edge of the macroscopic tumor. The Billroth II technique was used for reconstruction. For tumors of the gastric body and fundus, a total gastrectomy with a Roux-en-Y reconstruction was always performed. If localized carcinomatosis or involvement of adjacent organs was discovered, an en bloc resection was performed with curative intent.

The recommended standard lymphadenectomy with curative intent was D2 for antropyloric tumors and modified D2 (without splenectomy and left pancreatectomy; only performed in cases where there was involvement of these organs by the gastric tumor) for upper tumors requiring total gastrectomy. Both D2 and modified D2 are termed D2 lymphadenectomy in this work, in accordance with the guidelines of the Japanese Research Society for the Study of Gastric Cancer (JRSGC) [28]. D1 resection was an option, depending on patient status and tumor extent. Because of the lack of available control lymphadenectomies in this retrospective multicentric study, we classified lymphadenectomies in which 15-24 lymph nodes were harvested as D1 and those in which 25 or more lymph nodes were harvested as D2. Palliative resections were defined as microscopically or macroscopically incomplete (R1/R2). Simultaneous resection of localized carcinomatosis or hepatic metastasis was a possibility.

\section{Pathological analysis}

The histological classification of gastric carcinoma types followed the criteria of the WHO classification [13]. Diagnosis of an SRC tumor was based on the presence of isolated carcinoma cells containing mucin in the gastric adenocarcinoma. A predominant SRC component ( $>50 \%$ of the tumor) was usually observed, but the predominance of this component could not be ascertained precisely in this retrospective study. We therefore considered any tumor with a predominant $(>50 \%)$ SRC component and any diffuse-type gastric cancer with identified signet-ring cells (percentage not specified) to be an SRC gastric adenocarcinoma. Specimens were examined by pathologists experienced in digestive diseases. Retrieved lymph nodes, surgical margins, and the mural extension of the tumor were systematically assessed. TNM stages were defined according to the seventh edition of the UICC/TNM classification [29].

Curative resection (R0) was defined as macroscopically and microscopically complete resection. An R1 resection indicated microscopically positive margins and R2 indicated macroscopic residual tumor.

\section{Postoperative outcomes}

Morbidity and mortality at 30 and 90 days were recorded and classified according to Dindo and Clavien's classification of surgical complications [30] by retrospectively reviewing each patient record. Briefly, postoperative complications were ranked by severity based on the therapy used to treat the complications. A complication was classified grade I or II if it represented any deviation from the normal postoperative course or if it required any pharmacological treatment. Postoperative complications that were classified grade III required surgical, endoscopic, or radiological intervention, whereas complications that were classified grade IV represented life-threatening complications requiring intensive care unit management. A grade $\mathrm{V}$ complication corresponded to the death of the patient. 


\section{Follow-up}

Data on long-term ( $>90$ days) postoperative outcome were lacking in only 2 patients. Follow-up was performed in most centers every 6 months for at least 5 years, according to French guidelines [27]; each follow-up examination involved a physical examination, tumor marker measurement, and either abdominal ultrasound and chest radiography or a chest and abdominopelvic computed tomography scan.

\section{Statistical analysis}

Categorical data were compared using the chi-square test or Fisher's exact test. For continuous data, the independentsamples $t$-test was used. Survival rates and relapse rates were calculated using the Kaplan-Meier method and included postoperative deaths. Survival curves were calculated from the date of referral, and all causes of death were considered when estimating survival. The log-rank test was used to compare survival curves and to identify the prognostic factors of survival in univariate analysis. Multivariate analyses were performed using a Cox proportional hazards stepwise procedure, including nonredundant variables chosen by univariate analysis. A $p<0.2$ was necessary for systematic entry into the model. All statistical analyses were performed using SPSS version 19.0 (SPSS Inc., Chicago, IL, USA). A $p$ value $\leq 0.05$ was considered to indicate significance.

\section{Results}

\section{Preoperative data}

Table 1 summarizes the clinical characteristics of the whole studied population and shows the results of the univariate analysis of preoperative prognostic factors for overall survival. Median age at diagnosis was 67 years (range 21-100). Preoperative malnutrition was noted in 333 patients $(21.1 \%)$. Linitis was described on preoperative assessment for 241 patients (13.4\%).

At univariate analysis, the preoperative variables that were statistically significantly associated with poorer overall survival in the whole population were age $>60$ years, malnutrition, high American Society of Anesthesiologists (ASA) score, high clinical TNM stage, and linitis.

\section{Surgical management and postoperative outcome}

A total gastrectomy was performed in 979 patients $(54.4 \%)$. Seventy-four patients died within the first postoperative month, and 27 others in the next two months, accounting for postoperative mortality rates at 1 and 3 months of 4.1 and $5.6 \%$, respectively. Postoperative complications, either surgical or medical, occurred within the first and the third postoperative month in 664 patients $(36.9 \%)$ and 814 patients $(45.2 \%)$, respectively. At 1 month, according to Dindo-Clavien, complications were classified grade I or II in $328(18.2 \%)$ patients and grade III or IV in $262(14.6 \%)$ patients. At univariate analysis, the operative findings that were statistically associated with poorer overall survival were tumor involvement of the neighboring organs, distant metastasis, and peritoneal carcinomatosis (Table 2). Performance of a total gastrectomy, performance of a D1 lymphadenectomy, postoperative complication, and postoperative chemotherapy also adversely impacted overall survival.

\section{Histological data}

Among the 1799 patients included, 899 patients (50.0\%) were found to have SRC adenocarcinoma, as compared to 900 patients with non-SRC adenocarcinoma (50.0\%) (Table 2). Histological examination showed that $19.5 \%$ were early gastric cancers (pT0, pTis, or pT1) and $80.5 \%$ were more invasive tumors (T2, T3, T4). Sixty-five percent of the patients exhibited nodal metastases. The resection margin was R0 in 1528 patients $(85.0 \%)$.

Six histological variables were found to be associated with poor overall survival in univariate analysis: a positive resection margin ( $\mathrm{R} 0$ vs $\mathrm{R} 1 / \mathrm{R} 2), \mathrm{pT}, \mathrm{pN}, \mathrm{pM}$, and $\mathrm{pTNM}$ stages, and an SRC-type tumor. Thus, median survival in patients with non-SRC carcinoma was 51 months, as compared to 26 months in patients with SRC carcinoma $(p<0.001)$ (Fig. 1).

In order to better understand the impact of histological type on overall survival, a stage-stratified analysis was conducted (Fig. 2). When comparing stage I cancers, the survival of patients with SRC carcinoma was found to be longer than that of patients with the non-SRC type (median survival not reached, mean overall survival of 120 vs. 105 months; $p=0.043$ ). In stage II cancers, the prognosis of the SRC adenocarcinoma group was poorer than that of the non-SRC group, albeit not statistically significantly (43.9 vs. 129 months; $p=0.191$ ). Median survival for the stage III SRC group was significantly shorter than that for the stage III non-SRC group (18.8 vs. 25.1 months; $p=0.001)$. Survival of patients with stage IV SRC carcinoma did not vary significantly depending on the histological type of the tumor (10.1 months for SRC vs. 8.9 months for non-SRC, $p=0.576$ ).

\section{Comparison between SRC and non-SRC groups}

Females were more frequent in the SRC group (360/ $899=40.0$ vs $282 / 900=31.3 \%, p<0.001)$. To better understand the poor prognosis associated with SRC, we 
Table 1 Preoperative prognostic factors for overall survival in the whole population at univariate analysis

\begin{tabular}{|c|c|c|c|c|}
\hline \multirow[t]{2}{*}{ Variable } & \multirow[t]{2}{*}{$N=1799(\%)$} & \multicolumn{2}{|c|}{ Median survival } & \multirow[t]{2}{*}{$p$} \\
\hline & & Months & $95 \% \mathrm{CI}$ & \\
\hline Gender & & & & $<0.337$ \\
\hline Male & $1157(64.3)$ & 34.2 & $30.0-38.5$ & \\
\hline Female & $642(35.7)$ & 35.2 & $28.2-42.1$ & \\
\hline Age (years) & & & & $<0.001$ \\
\hline$\leq 60$ & $1198(66.6)$ & 43.0 & $30.9-55.1$ & \\
\hline$>60$ & $601(34.4)$ & 31.8 & $30.0-55.1$ & \\
\hline Malnutrition & & & & $<0.001$ \\
\hline No & $1322(73.5)$ & 41.9 & $34.3-49.4$ & \\
\hline Yes & $333(18.5)$ & 19.2 & $16.6-21.8$ & \\
\hline Unknown & $144(8.0)$ & & & \\
\hline ASA score & & & & $<0.001$ \\
\hline 1 & $518(28.8)$ & 42.6 & $30.9-54.2$ & \\
\hline 2 & $832(46.2)$ & 39.2 & $29.3-49.0$ & \\
\hline 3 & $418(23.2)$ & 23.2 & $19.3-27.0$ & \\
\hline 4 & $31(1.7)$ & 12.2 & & \\
\hline Pretherapeutic cTNM stage & & & & $<0.001$ \\
\hline I & $470(26.1)$ & $\mathrm{nr}$ & $27.4-59.2$ & \\
\hline II & $396(22.0)$ & 43.3 & & \\
\hline III & $858(47.7)$ & 23.0 & $21.1-24.9$ & \\
\hline IV & $75(4.2)$ & 11.1 & $08.1-14.0$ & \\
\hline Linitis & & & & $<0.001$ \\
\hline No & $1558(86.6)$ & 41.1 & $35.0-47.3$ & \\
\hline Yes & $241(13.4)$ & 17.7 & $15.2-20.1$ & \\
\hline Antropyloric location & & & & $<0.215$ \\
\hline No & $1043(58.0)$ & 30.8 & $25.9-35.8$ & \\
\hline Yes & $756(42.0)$ & 35.1 & $29.9-40.3$ & \\
\hline Preoperative chemotherapy & & & & $<0.172$ \\
\hline No & $1509(83.9)$ & 36.7 & $31.9-41.4$ & \\
\hline Yes & $290(16.1)$ & 27.3 & $23.3-31.2$ & \\
\hline
\end{tabular}

$n r$ median survival not reached, ASA America Society of Anesthesiology compared the SRC and non-SRC groups in terms of the prevalence of each prognostic factor identified by the previous univariate analysis (Table 3). Patients in the SRC group were significantly younger, had lower ASA scores, and were more likely to have preoperative malnutrition. Linitis, pT3-T4 tumors (61.3 vs $23.8 \%$ ), and nodal and peritoneal metastases were more frequent in the SRC tumor group. Accordingly, resections in this latter group were more often palliative (R1-R2), and postoperative CT was used more frequently. All of these differences were statistically significant. The factors that were prognostic in the univariate analysis were all included in the multivariate analysis.

\section{Prognostic factors for overall survival}

In the multivariate analysis, neither the type of gastrectomy (subtotal or total) nor preoperative chemotherapy were found to be prognostic for overall survival (Table 4). Postoperative chemotherapy, which appeared to be associated with poorer overall survival in the univariate analysis, was instead identified as a protective factor in the multivariate analysis.

The other 12 variables examined in the multivariate analysis, including postoperative complication and extent of lymphadenectomy, remained significantly associated with overall survival. Thus, SRC type remained a significant and independent adverse prognostic factor $(\mathrm{HR}=1.182)$.

Because advanced disease was seen more frequently in SRC patients, which meant that incomplete resections were also more frequent in this group, a multivariate analysis was performed on the R0 population. This multivariate analysis confirmed the independent pejorative prognosis of SRC type in this R0 population (see Online Resource 1 in the Electronic supplementary material, ESM). 
Table 2 Pre- and postoperative prognostic factors for overall survival in the whole population at univariate analysis

\begin{tabular}{|c|c|c|c|c|}
\hline \multirow[t]{2}{*}{ Variable } & \multirow[t]{2}{*}{$N=1799(\%)$} & \multicolumn{2}{|c|}{ Median survival } & \multirow[t]{2}{*}{$p$} \\
\hline & & Months & $95 \% \mathrm{CI}$ & \\
\hline Involvement of neighboring organs & & & & $<0.001$ \\
\hline No & 1548 (85.4) & 41.3 & $34.6-48.0$ & \\
\hline Yes & $251(14.6)$ & 14.6 & $12.4-16.8$ & \\
\hline Distant metastasis & & & & $<0.001$ \\
\hline No & $1732(96.3)$ & 36.9 & $32.5-41.2$ & \\
\hline Yes & $67(3.7)$ & 10.5 & $08.5-12.5$ & \\
\hline Peritoneal carcinomatosis & & & & $<0.001$ \\
\hline No & 1672 (92.9) & 39.2 & $34.1-44.2$ & \\
\hline Yes & $127(7.1)$ & 11.6 & $10.0-13.2$ & \\
\hline Gastrectomy & & & & $<0.001$ \\
\hline Total & $979(54.4)$ & 30.2 & $25.9-34.6$ & \\
\hline Subtotal & $820(45.6)$ & 39.3 & $29.2-49.3$ & \\
\hline Number of lymph nodes retrieved & & & & $<0.001$ \\
\hline$<25$ lymph nodes & $383(21.3)$ & 26.6 & $21.5-31.8$ & \\
\hline$>25$ lymph nodes & $1230(68.4)$ & 40.1 & $34.3-46.0$ & \\
\hline Missing data & $186(10.3)$ & & & \\
\hline Postoperative complication & & & & $<0.001$ \\
\hline No & $985(54.8)$ & 43.2 & $36.2-50.1$ & \\
\hline Yes & $814(45.2)$ & 24.9 & $20.8-29.0$ & \\
\hline Postoperative chemotherapy & & & & $<0.027$ \\
\hline No & $1174(65.3)$ & 40.8 & $33.7-47.9$ & \\
\hline Yes & $625(34.7)$ & 28.9 & $25.5-32.3$ & \\
\hline pT stage & & & & $<0.001$ \\
\hline pT0 & $27(1.5)$ & $\mathrm{nr}$ & & \\
\hline pTis & $28(1.6)$ & $\mathrm{nr}$ & & \\
\hline pT1 & $296(16.5)$ & $\mathrm{nr}$ & & \\
\hline pT2 & $590(32.8)$ & 55.4 & $42.0-68.7$ & \\
\hline pT3 & 604 (33.6) & 21.0 & $19.1-22.8$ & \\
\hline pT4 & $254(14.1)$ & 16.3 & $13.5-19.1$ & \\
\hline pN stage & & & & $<0.001$ \\
\hline pN0 & $637(35.4)$ & 148.1 & & \\
\hline $\mathrm{pN} 1$ & $572(31.8)$ & 37.7 & $32.1-43.4$ & \\
\hline $\mathrm{pN} 2$ & $372(20.7)$ & 18.8 & $17.0-20.6$ & \\
\hline $\mathrm{pN} 3$ & $218(12.18)$ & 15.2 & $12.5-17.8$ & \\
\hline \multicolumn{5}{|l|}{ pM stage } \\
\hline $\mathrm{pM} 0$ & $1598(88.8)$ & 42.2 & $35.5-48.2$ & $<0.001$ \\
\hline $\mathrm{pM} 1$ & $201(11.2)$ & 11.7 & $10.1-13.3$ & \\
\hline \multicolumn{5}{|l|}{ pTNM stage } \\
\hline Stage I & $541(30.1)$ & $\mathrm{nr}$ & & $<0.001$ \\
\hline Stage II & $310(17.2)$ & 54.3 & $13.8-94.9$ & \\
\hline Stage III & $747(41.5)$ & 22.8 & $20.9-24.8$ & \\
\hline Stage IV & $201(11.2)$ & 11.7 & $10.2-13.1$ & \\
\hline \multicolumn{5}{|l|}{ Histological type } \\
\hline Non-SRC & $900(50.0)$ & 51.1 & $39.2-63.1$ & $<0.001$ \\
\hline $\mathrm{SRC}$ & $899(50.0)$ & 26.2 & $23.0-29.4$ & \\
\hline \multicolumn{5}{|l|}{ Resection } \\
\hline R0 & $1528(84.9)$ & 47.0 & $39.4-54.7$ & $<0.001$ \\
\hline $\mathrm{R} 1$ & $186(10.3)$ & 15.4 & $13.4-17.3$ & \\
\hline $\mathrm{R} 2$ & $85(4.7)$ & 9.0 & $05.9-12.1$ & \\
\hline
\end{tabular}

$n r$ median survival not reached 
Fig. 1 Survival curves for the non-SRC and SRC groups. The number of subjects at risk at each interval is shown in the table at the bottom of the graph

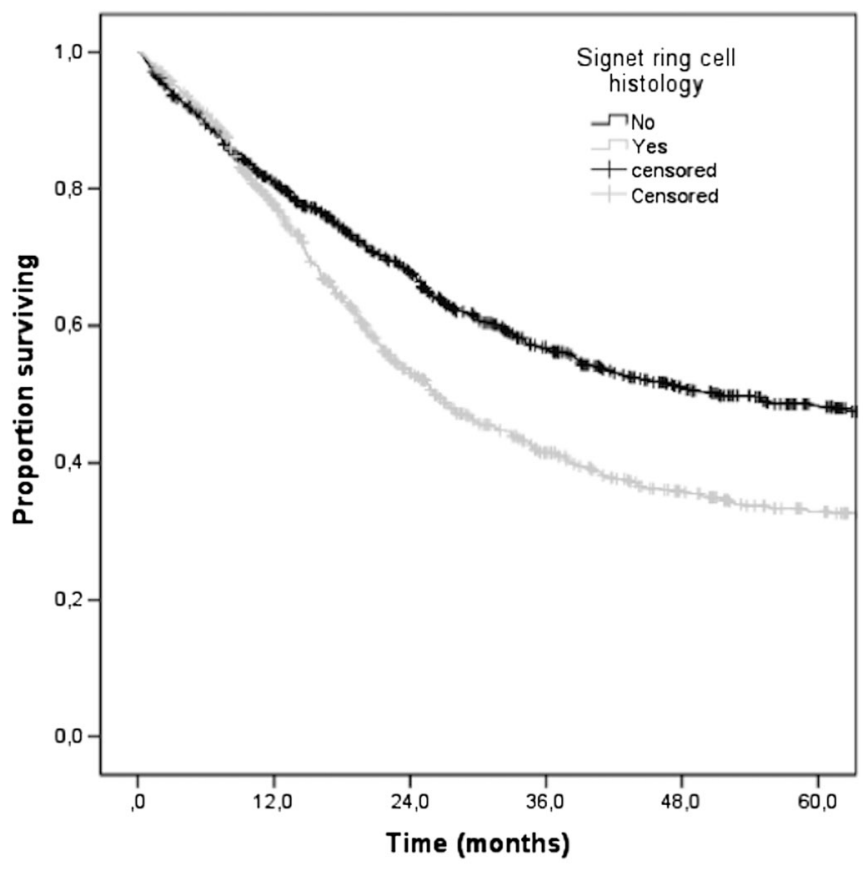

\begin{tabular}{|l|c|c|c|c|c|c|}
\hline Non SRC & 900 & 684 & 512 & 368 & 281 & 223 \\
\hline SRC & 899 & 657 & 395 & 260 & 191 & 147 \\
\hline
\end{tabular}

\section{Specific prognostic factors for overall survival in SRC adenocarcinoma}

As the two histological types of gastric adenocarcinoma had distinct presentations and prognoses, a subgroup multivariate analysis based on histological type was conducted to determine whether the SRC and non-SRC gastric adenocarcinoma groups exhibit distinct prognostic factors for overall survival.

In the non-SRC group, the independent adverse prognostic factors for overall survival were high ASA score, preoperative malnutrition, limited lymphadenectomy, postoperative complication, high histological $\mathrm{T}$ or $\mathrm{N}$ stage, and a positive margin (Table 5). Preoperative chemotherapy was also associated with poorer overall survival, whereas postoperative chemotherapy was statistically associated with better survival.

The prognostic factors that were independently associated with poor survival differed somewhat for the SRC group (Table 5). Age older than 60 years, linitis, and involvement of adjacent organs were statistically associated with poor survival, but administration of preoperative or postoperative chemotherapy did not independently influence survival in the SRC group.

\section{Prognostic factors for relapse-free survival}

Among the 1799 patients included in the study, 152 were treated by performing a complete (R0) resection. The relapse rate in the $\mathrm{R} 0$ patients followed-up during this study was $41.36 \%$ (632 patients). During follow-up, a relapse of the cancer occurred in 304 patients (37.49\%) in the non-SRC group and 328 patients $(45.75 \%)$ in the SRC group $(p<0.001)$.

Online Resource 2 in the ESM presents the results of the multivariate analysis performed to assess independent prognostic factors for relapse-free survival in the R0 population. Among the variables included in the Cox model, 12 independent prognostic factors were identified, including age older than 60 years, high ASA score, preoperative malnutrition, neoadjuvant chemotherapy, linitis, involvement of adjacent organs, number of lymph nodes retrieved, postoperative complications, $\mathrm{pT}$ stage, $\mathrm{pN}$ stage, $\mathrm{pM}$ stage, and SRC-type tumor.

\section{Discussion}

Despite improvements in diagnostic tools and changes in therapeutic strategy during the last decade in Europe, overall survival for patients with gastric cancer remains poor, with a mean age-standardized 5-year relative survival rate of $25.1 \%$ [31]. Moreover, several recent studies have reported a decreased incidence of gastric adenocarcinoma but an increased incidence of the SRC type of gastric adenocarcinoma in Western countries [2]; this type accounted for $35-45.4 \%$ of gastric ADC cases in recent studies [4, 5, 7, 8]. Given the worse prognosis of the SRC type than the non-SRC 

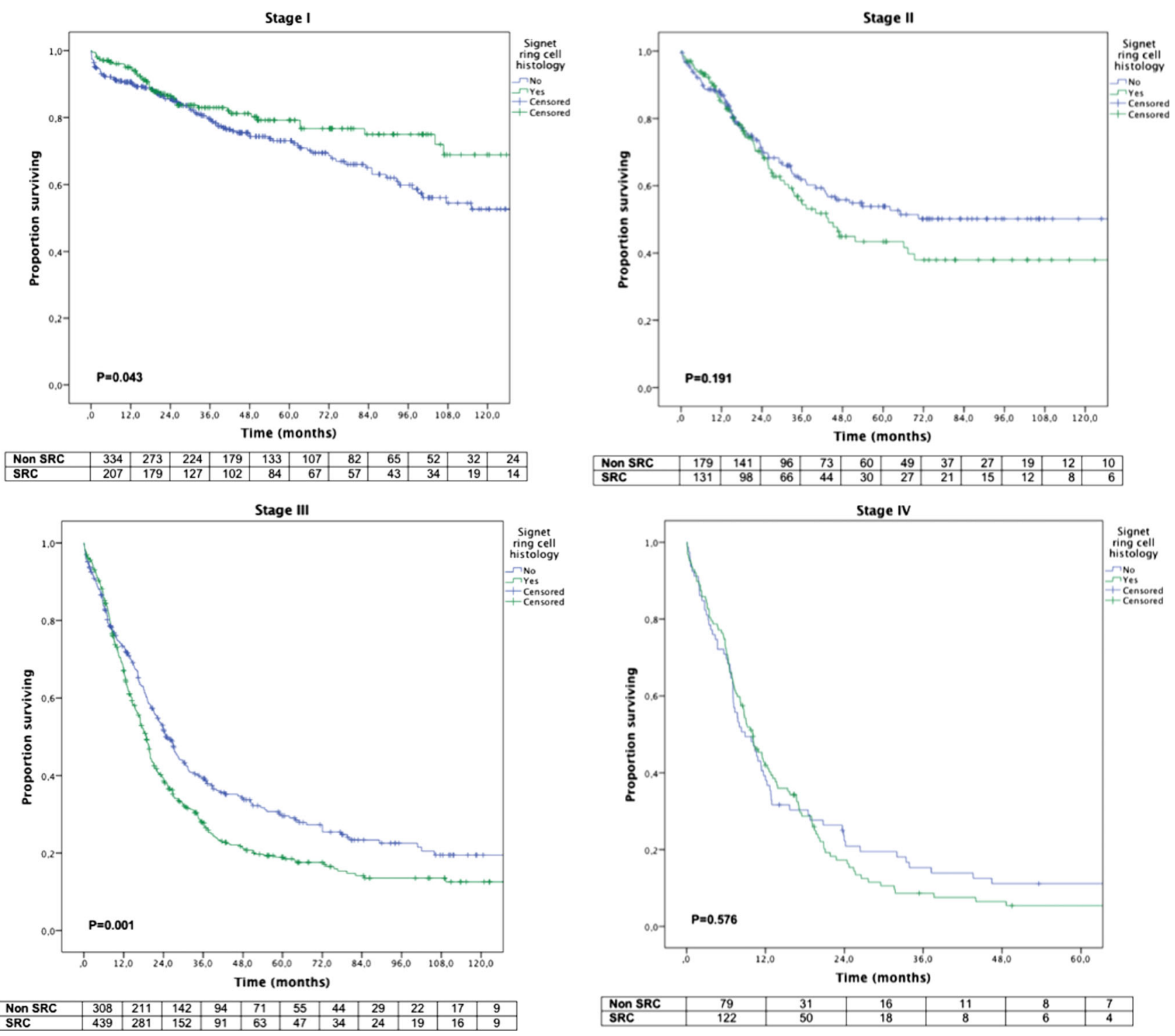

Fig. 2 Stage-stratified survival curves for the non-SRC and SRC groups

type, it may be that the increased incidence of the SRC type is contributing to the lack of improvement in overall survival of patients with gastric cancer. However, studies supporting this hypothesis are rare, especially in Europe, where only one retrospective single-center case-matched study addressing this issue has been published [5].

In the present study, using a large multicenter retrospective cohort of 1799 resected gastric carcinoma cases between January 1997 and March 2010, we confirmed that SRC histological type is an independent prognostic factor for mortality $(\mathrm{HR}=1.182 ; p=0.041)$ and for disease-free survival $(\mathrm{HR}=1.227 ; p=0.019)$ according to multivariate analysis when adjustments are made for other prognostic factors such as malnutrition, linitis, completeness of resection, tumor extension (pT stage), lymph node invasion (pN stage), and presence of distant metastasis.
In early gastric cancer (mostly described in Asian countries), it is clearly established that the prognosis of the SRC type is better than that of the non-SRC type $[8,10,18$, $19,32]$, probably because the SRC-type tumor is more frequently confined to the mucosa and shows a lower rate of lymph node metastasis [18, 32]. This observed better survival may be related to the younger age of patients with SRC gastric cancer [20].

In contrast, the prognostic value of histological type in cases of advanced gastric carcinoma is still controversial. Thus, numerous studies from Asia have demonstrated that the SRC type was more frequently diagnosed at a later stage, with a higher proportion of such tumors invading subserosa (pT3) or serosa (pT4); a higher rate of lymph node metastasis is also seen for the SRC type [7, 10, 33, 34]. Furthermore, unsuspected peritoneal carcinomatosis 
Table 3 Distribution of factors prognostic for overall survival in the non-SRC and SRC groups

\begin{tabular}{|c|c|c|c|}
\hline Variable & Non-SRC $N=900$ & SRC $N=899$ & $p$ \\
\hline Gender: male & $618(68.7)$ & $539(59.9)$ & $<0.001$ \\
\hline Age $>60$ years & $697(77.4)$ & $502(55.8)$ & $<0.001$ \\
\hline ASA score & & & $<0.001$ \\
\hline 1 & $212(23.5)$ & $306(34.0)$ & \\
\hline 2 & $430(47.8)$ & $402(44.7)$ & \\
\hline 3 & $238(26.4)$ & $180(20.0)$ & \\
\hline 4 & $20(2.3)$ & $11(1.3)$ & \\
\hline Malnutrition (missing data in 144 cases) & $150(17.9)$ & $183(22.4)$ & $<0.022$ \\
\hline cTNM stage & & & $<0.001$ \\
\hline Stage I & $275(30.6)$ & $195(21.7)$ & \\
\hline Stage II & $211(23.4)$ & $185(20.6)$ & \\
\hline Stage III & $387(43.0)$ & $471(52.4)$ & \\
\hline Stage IV & $27(3.0)$ & $48(5.3)$ & \\
\hline Linitis & $19(2.1)$ & $222(24.7)$ & $<0.001$ \\
\hline Preoperative chemotherapy & $131(14.6)$ & $159(17.7)$ & $<0.071$ \\
\hline Involvement of adjacent organs & $107(11.9)$ & $144(16.0)$ & $<0.011$ \\
\hline Distant metastasis & $34(3.8)$ & $33(3.7)$ & $<0.905$ \\
\hline Ascites/carcinomatosis & $39(4.3)$ & $88(9.8)$ & $<0.001$ \\
\hline Total gastrectomy & $433(48.1)$ & $546(60.7)$ & $<0.001$ \\
\hline Number of lymph nodes retrieved (mean \pm SD) & $23.85 \pm 12.47$ & $26.41 \pm 13.81$ & $<0.001$ \\
\hline Postoperative complication (90 days) & $427(47.4)$ & $387(43.0)$ & $<0.061$ \\
\hline Postoperative chemotherapy & $251(27.9)$ & $374(41.6)$ & $<0.001$ \\
\hline pT stage & & & $<0.001$ \\
\hline pT0-pTis-pT1 & $212(23.5)$ & $139(15.5)$ & \\
\hline pT2 & $338(37.5)$ & $252(28.0)$ & \\
\hline pT3 & $243(27.0)$ & $361(40.2)$ & \\
\hline pT4 & $107(14.8)$ & $147(21.1)$ & \\
\hline $\mathrm{pN}$ stage & & & $<0.001$ \\
\hline pN0 & $396(44.0)$ & $241(26.8)$ & \\
\hline $\mathrm{pN} 1$ & $290(32.2)$ & $282(31.4)$ & \\
\hline $\mathrm{pN} 2$ & $162(18.0)$ & $210(23.4)$ & \\
\hline $\mathrm{pN} 3$ & $52(5.8)$ & $166(18.5)$ & \\
\hline pM1 stage & $79(8.8)$ & $122(13.6)$ & $<0.001$ \\
\hline pTNM stage & & & $<0.001$ \\
\hline Stage I & $334(37.1)$ & $207(23.0)$ & \\
\hline Stage II & 179 (19.9) & 131 (14.6) & \\
\hline Stage III & $308(34.2)$ & 439 (48.8) & \\
\hline Stage IV & $79(8.8)$ & 122 (13.6) & \\
\hline Resection R1-R2 & $89(9.9)$ & $182(20.2)$ & $<0.001$ \\
\hline
\end{tabular}

was found more frequently during surgery in patients with SRC-type gastric carcinoma [7, 33, 35]. Accordingly, Asian studies reported that the SRC histological type exhibited a lower curative resection rate and was associated with poorer overall survival [7, 10, 11, 22].

Although gastric adenocarcinoma seems to behave differently in Asian and Western countries [36, 37], the four studies performed in the United States and Europe that have compared SRC with non-SRC gastric adenocarcinoma obtained similar results [4, 5, 23, 38]. As also noted in those studies, we found that the SRC type was associated with a lower curative resection rate 79.8 vs $90.1 \% ; p<0.001)$ and poorer median overall survival (26.2 \pm 1.62 vs $51.13 \pm 6.09$ months; $p<0.001)$ than the non-SRC subtype, with significantly more frequent involvement of adjacent organs (16 vs $11.9 \%$ ), linitis (24.7 vs $2.1 \%)$, peritoneal carcinomatosis (9.8 vs $4.3 \%)$, advanced T stage (61.3 vs $41.8 \%$ of pT3 and pT4 stage), 
Table 4 Prognostic factors for overall survival at multivariate analysis for the whole population

Table 5 Prognostic factors for overall survival at multivariate analysis for patients with signet ring cell (SRC) carcinoma and patients with non-SRC carcinoma

\begin{tabular}{lrrrr}
\hline Variable & \multicolumn{1}{l}{$X^{2}$} & HR & $95 \%$ CI & $p$ \\
\hline Age $>60$ years & 10.225 & 1.330 & $1.117-1.584$ & $<0.001$ \\
ASA score & 20.531 & 1.265 & $1.143-1.401$ & $<0.001$ \\
Cancer-related malnutrition & 17.760 & 1.432 & $1.212-1.692$ & $<0.001$ \\
Preoperative chemotherapy & 3.437 & 1.207 & $0.989-1.474$ & $<0.064$ \\
Linitis & 5.133 & 1.252 & $1.031-1.521$ & $<0.023$ \\
Involvement of adjacent organs & 9.780 & 1.360 & $1.122-1.650$ & $<0.002$ \\
Total or subtotal gastrectomy & 0.048 & 1.018 & $0.869-1.193$ & $<0.826$ \\
More than 25 lymph nodes retrieved & 8.640 & 0.770 & $0.647-0.917$ & $<0.003$ \\
Postoperative complication (90 days) & 15.443 & 1.334 & $1.155-1.540$ & $<0.001$ \\
Postoperative chemotherapy & 7.137 & 0.802 & $0.683-0.943$ & $<0.008$ \\
SRC tumor & 4.182 & 1.182 & $1.007-1.387$ & $<0.041$ \\
pT stage & 25.990 & 1.243 & $1.143-1.352$ & $<0.001$ \\
pN stage & 153.842 & 1.638 & $1.515-1.771$ & $<0.001$ \\
pM stage & 4.326 & 1.257 & $1.013-1.560$ & $<0.038$ \\
Completeness of resection R0/R1/R2 & 18.469 & 1.372 & $1.188-1.585$ & $<0.001$ \\
\hline
\end{tabular}

\begin{tabular}{|c|c|c|c|c|c|}
\hline Group & Variable & $X^{2}$ & HR & $95 \% \mathrm{CI}$ & $p$ \\
\hline \multirow[t]{14}{*}{ Non-SRC } & Age $>60$ years & 0.809 & 1.149 & $0.849-1.553$ & $<0.368$ \\
\hline & ASA score & 14.532 & 1.343 & $1.154-1.563$ & $<0.001$ \\
\hline & Cancer-related malnutrition & 17.913 & 1.767 & $1.358-2.300$ & $<0.001$ \\
\hline & Preoperative chemotherapy & 6.575 & 1.515 & $1.103-2.082$ & $<0.010$ \\
\hline & Linitis & 0.028 & 0.947 & $0.503-1.784$ & $<0.867$ \\
\hline & Involvement of adjacent organs & 1.850 & 1.232 & $0.912-1.664$ & $<0.174$ \\
\hline & Total or subtotal gastrectomy & 1.115 & 1.131 & $0.900-1.423$ & $<0.291$ \\
\hline & More than 25 lymph nodes retrieved & 4.802 & 0.752 & $0.583-0.970$ & $<0.028$ \\
\hline & Postoperative complication (90 days) & 8.600 & 1.399 & $1.118-1.750$ & $<0.003$ \\
\hline & Postoperative chemotherapy & 7.660 & 0.692 & $0.534-0.898$ & $<0.006$ \\
\hline & pT stage & 7.186 & 1.180 & $1.045-1.331$ & $<0.007$ \\
\hline & $\mathrm{pN}$ stage & 69.007 & 1.729 & $1.520-1.968$ & $<0.001$ \\
\hline & pM stage & 1.809 & 1.281 & $0.893-1.837$ & $<0.179$ \\
\hline & Completeness of resection $\mathrm{R} 0 / \mathrm{R} 1 / \mathrm{R} 2$ & 13.151 & 1.518 & $1.211-1.902$ & $<0.001$ \\
\hline \multirow[t]{14}{*}{ SRC } & Age $>60$ years & 14.133 & 1.513 & $1.219-1.877$ & $<0.001$ \\
\hline & ASA score & 5.231 & 1.179 & $1.024-1.358$ & $<0.022$ \\
\hline & Cancer-related malnutrition & 5.249 & 1.291 & $1.038-1.606$ & $<0.022$ \\
\hline & Preoperative chemotherapy & 0.205 & 1.062 & $0.819-1.376$ & $<0.651$ \\
\hline & Linitis & 5.406 & 1.291 & $1.041-1.601$ & $<0.020$ \\
\hline & Involvement of adjacent organs & 9.960 & 1.500 & $1.166-1.930$ & $<0.002$ \\
\hline & Total or subtotal gastrectomy & 0.841 & 0.900 & $0.718-1.128$ & $<0.359$ \\
\hline & More than 25 lymph nodes retrieved & 4.350 & 0.774 & $0.609-0.985$ & $<0.037$ \\
\hline & Postoperative complication (90 days) & 7.036 & 1.297 & $1.070-1.572$ & $<0.008$ \\
\hline & Postoperative chemotherapy & 1.609 & 0.873 & $0.708-1.077$ & $<0.205$ \\
\hline & pT stage & 22.094 & 1.336 & $1.184-1.508$ & $<0.001$ \\
\hline & $\mathrm{pN}$ stage & 84.998 & 1.592 & $1.442-1.757$ & $<0.001$ \\
\hline & pM stage & 2.169 & 1.229 & $0.934-1.617$ & $<0.141$ \\
\hline & Completeness of resection $\mathrm{R} 0 / \mathrm{R} 1 / \mathrm{R} 2$ & 6.070 & 1.272 & $1.050-1.539$ & $<0.014$ \\
\hline
\end{tabular}


and lymph node involvement (73.2 vs $56 \%$ ). However, we also found that SRC adenocarcinoma still had a poor prognosis after including these potential confounding factors in the multivariate analyses of the whole population and the R0 population, suggesting that SRC histological type is an independent adverse prognostic factor for overall survival in gastric carcinoma cases. This result is concordant with a previous French retrospective and single-center study of 180 patients [5], and is also in line with an Asian study that used multivariate analysis and found that the SRC type was associated with a poorer prognosis, albeit not statistically significantly so [35]. In contrast, among the five multivariate studies available [39-44] on the prognostic impact of SRC type in gastric adenocarcinoma, the single Western study did not find any impact of SRC type on survival [23], but Taghavi et al. acknowledged that although radicality of surgery (R0 or R1-R2) and extent of lymphadenectomy were found to be prognostic factors for overall survival in the literature (and in our multivariate analysis) [39-44], these factors were neither controlled nor recorded in their retrospective analysis of the large SEER database [23].

Among the prognostic factors for poor survival found in our study, three are characteristics of patients: patient older than 60 years $(\mathrm{HR}=1.33 ; p=0.001)$, high ASA score (HR $=1.265 ; p<0.001)$, and preoperative malnutrition $(\mathrm{HR}=1.432 ; p<0.001)$. Although age has usually been included in analyses of prognostic factors for survival in gastric cancer, the two other factors were not previously included in multivariate analyses, prognostic indices, or nomograms reporting patient outcomes after gastrectomy for gastric cancer [45, 46]. However, several studies have shown that malnutrition-which was observed in $21 \%$ of oncological patients [47] (as in our study) — significantly increases mortality after surgery for cancer [48-51]. Further studies should therefore systematically include nutritional status in their prognostic analyses.

Interestingly, postoperative chemotherapy was found to be an independent favorable prognostic factor for survival ( $\mathrm{HR}=0.802 ; p=0.008)$, as demonstrated with identical hazard ratio in two recent patient-level meta-analyses [52, 53] and in the CLASSIC randomized controlled trial [54, 55]. Our retrospective study suggests that adjuvant chemotherapy may have more impact than neoadjuvant chemotherapy, but this observation could be biased by the retrospective design of this study, with selective administration of neoadjuvant chemotherapy to more aggressive tumors and of adjuvant chemotherapy to patients without postoperative morbidity. Although perioperative chemotherapy has been adopted as the standard treatment in Europe, the respective merits of pre- and postoperative chemotherapy deserve further study.
The differences in presentation at diagnosis between SRC and non-SRC gastric carcinoma and the independent prognostic value of SRC type for overall survival support the emerging concept that SRC carcinoma is a distinct disease. This concept is supported by recent results of a large molecular and genomic analysis of gastric cancers by the Cancer Genome Atlas Research Network, which defined four major genomic gastric cancer subtypes [58]. Among these, genomically stable tumors (GS tumors), which were predominantly associated with the diffuse type in the Lauren classification, share some characteristics with SRC adenocarcinoma in the WHO classification. Thus, GS tumors were associated with RHOA mutations and CLDN18-ARHGAP fusion, which contribute to the invasive phenotype of this subtype of gastric cancer, exhibiting CDH1 mutations and deficient cell adhesion.

In line with this new concept, we have individualized distinct independent prognostic factors for SRC and nonSRC gastric adenocarcinoma. Although classical prognostic factors for overall survival were found for both of these types of gastric carcinoma (e.g., pT stage, pN stage, completeness of resection, extent of lymphadenectomy, and postoperative complications), a few prognostic factors appear to be specific to only one histological type. Thus, linitis, involvement of adjacent organs, and age $>60$ years were found to alter survival in patients with SRC carcinoma but were not statistically associated with poorer survival in patients with non-SRC carcinoma. Similarly, postoperative chemotherapy was efficient in the non-SRC group but did not impact on survival in the SRC group, whereas preoperative chemotherapy was associated with poorer survival in the non-SRC group but had no significant impact in the SRC group. This latter observation contrasts with results from a previous study by our group, which identified preoperative chemotherapy as an adverse prognostic factor for overall survival in SRC adenocarcinoma patients [6]. This discrepancy could be partly due to the inclusion of tumors of the esophagogastric junction in the first study [56]. Moreover, important prognostic factors identified in our more recent analysis, such as age, involvement of adjacent organs, extent of lymphadenectomy, and $\mathrm{T}, \mathrm{N}$, and $\mathrm{M}$ components of the TNM classification, were not included in the multivariate analysis performed in the first study. To better investigate the chemosensitivity of SRC carcinoma, an ongoing prospective randomized multicentric trial has been launched by our FREGAT group (NCT01717924) [57].

In conclusion, although SRC gastric adenocarcinoma is usually diagnosed at a more advanced stage, our study demonstrates that SRC histological type is a major and independent prognostic factor for overall survival in gastric cancer. This histological type should be considered a 
distinct disease among gastric cancers, with its own specific prognostic factors.

Moreover, stratification according to the SRC component is warranted in further studies of chemosensitivity and response to (neo)adjuvant chemotherapy because SRC tumors may require distinct perioperative therapeutic strategies. Those future studies should take into account the specific prognostic factors for SRC tumors identified in our study.

Acknowledgments Collaborators: FREGAT working groupFRENCH: Jean Pierre Arnaud, MD (Department of Digestive Surgery, Angers University Hospital, Angers, France); Jean Michel Balon, MD (Department of Digestive Surgery, Clinique Jules Verne Nantes, France); Frank Bonnetain, PhD (Biostatistics and Epidemiological Unit of the Georges François Leclerc Center, Dijon, France); Frederic Borie, MD, PhD (Department of Digestive Surgery, Nîmes University Hospital, Nimes, France); Dorothée Brachet, MD (Department of Digestive Surgery, Angers University Hospital, Angers, France); Nicolas Carrere, MD, PhD (Department of Digestive Surgery, Toulouse University Hospital, Toulouse, France); Xavier Benoit D'Journo, MD, PhD (Department of Digestive Surgery, Nord University Hospital Marseille, France); Pierre Dechelotte, MD, PhD (Department of Pathology, Clermont-Ferrand University Hospital, Clermont-Ferrand, France); Jean Robert Delpero, MD (Department of Digestive Surgery, Paoli Calmette Institute Marseille, France); Abdenaceur Dhari, MD (Department of Digestive Surgery, Amiens University Hospital, Amiens, France); Sylvain Fabre, MD (Department of Digestive Surgery, Clinique Jules Verne Nantes, France); Manuel Fernandez, MD (Department of Digestive Surgery, Strasbourg University Hospital, Strasbourg, France); Renaud Flamein, MD (Department of Digestive Surgery, Clermont-Ferrand University Hospital, Clermont-Ferrand, France); Brigitte Gillet (Department of Digestive Surgery, Clermont-Ferrand University Hospital, ClermontFerrand, France); Aude Glaise, MD (Department of Digestive Surgery, Montpellier University Hospital, Montpellier, France); Marie Guilbert (Department of Digestive Surgery, Lille University Hospital, Lille, France), Jérôme Guiramand, MD (Department of Digestive Surgery, Paoli Calmette Institute Marseille, France); Mohamed Hebbar, MD, PhD (Department of Medical Oncology, Lille University Hospital, Lille, France); Noël Huten, MD (Department of Digestive Surgery, Tours University Hospital, Tours, France); Kevin Kraft, MD (Department of Digestive Surgery, Tours University Hospital, Tours, France); Emmanuelle Leteurtre, MD, PhD (Department of Pathology, Lille University Hospital, Lille, France); Damien Louis, MD (Department of Digestive Surgery, Toulouse University Hospital, Toulouse, France); Benjamin Mathieu (Department of Digestive Surgery, Clermont-Ferrand University Hospital, ClermontFerrand, France); Sophie Michalak, MD (Department of Pathology, Angers University Hospital, Angers, France); Francis Michot, MD (Department of Digestive Surgery, Rouen University Hospital, Rouen, France); Bertrand Millat, MD (Department of Digestive Surgery, Montpellier University Hospital, Montpellier, France); Frédérique Peschaud, MD, $\mathrm{PhD}$ (Department of Digestive Surgery, Ambroise Paré University Hospital, Boulogne-Billancourt, France); Denis Pezet, MD, PhD (Department of Digestive Surgery, ClermontFerrand University Hospital, Clermont-Ferrand, France); Virginie Pichot-Delahaye, MD (Department of Digestive Surgery, Lyon University Hospital, Lyon, France); Marc Pocard, MD, PhD (Department of Digestive Surgery, Lariboisière University Hospital, Paris, France); Ariane Poisson, PharmD (AP Department of Digestive Surgery, Lille University Hospital, Lille, France); Michel Prudhomme, MD (Department of Digestive Surgery, Nîmes University
Hospital, Nîmes, France); Jean Marc Regimbeau, MD, PhD (Department of Digestive Surgery, Amiens University Hospital, Amiens, France); Amine Souadka, MD (Department of Digestive Surgery, Gustave Roussy Institute Villejuif, France); Timothée Thiébot, MD (Department of Digestive Surgery, Rennes University Hospital, Rennes, France); Pascal-Alexandre Thomas, MD (Department of Digestive Surgery, Nord University Hospital Marseille, France); Basile Tsilividis, MD (Department of Digestive Surgery, Rouen University Hospital, Rouen, France); and Florence Vandois, MD (Department of Digestive Surgery, Lille University Hospital, Lille, France).

\section{Compliance with ethical standards}

Conflicts of interest The authors declare that they have nothing to disclose.

Ethical statement All procedures followed were in accordance with the ethical standards of the responsible committee on human experimentation (institutional and national) and with the Declaration of Helsinki of 1964 and later versions. Informed consent or a substitute for it was obtained from all patients before they were included in the study.

\section{References}

1. Ferlay J, Soerjomataram II, Dikshit R, Eser S, Mathers C, Rebelo $\mathrm{M}$, et al. Cancer incidence and mortality worldwide: sources, methods and major patterns in GLOBOCAN. Int $\mathrm{J}$ Cancer. 2012;2014:386.

2. Henson DE, Dittus C, Younes M, Nguyen H, Albores-Saavedra J. Differential trends in the intestinal and diffuse types of gastric carcinoma in the United States, 1973-2000: increase in the signet ring cell type. Arch Pathol Lab Med. 2004;128:765-70.

3. Hass HG, Smith U, Jäger C, Schäffer M, Wellhäußer U, Hehr T, et al. Signet ring cell carcinoma of the stomach is significantly associated with poor prognosis and diffuse gastric cancer (Lauren's): single-center experience of 160 cases. Onkologie. 2011;34:682-6.

4. Theuer C, Nastanski F, Brewster W, Butler J, Anton-Culver H. Signet ring cell histology is associated with unique clinical features but does not affect gastric cancer survival. Am Surg. 1999;65:915-21.

5. Piessen G, Messager M, Leteurtre E, Jean-Pierre T, Mariette C. Signet ring cell histology is an independent predictor of poor prognosis in gastric adenocarcinoma regardless of tumoral clinical presentation. Ann Surg. 2009;250:878-87.

6. Messager M, Lefevre JH, Pichot-Delahaye V, Souadka A, Piessen $\mathrm{G}$, Mariette C. The impact of perioperative chemotherapy on survival in patients with gastric signet ring cell adenocarcinoma: a multicenter comparative study. Ann Surg. 2011;254:684-93.

7. Li C, Kim S, Lai JF, Hyung WJ, Choi WH, Choi SH, et al. Advanced gastric carcinoma with signet ring cell histology. Oncology. 2007;72:64-8.

8. Kunisaki C, Shimada H, Nomura M, Matsuda G, Otsuka Y, Akiyama $\mathrm{H}$. Therapeutic strategy for signet ring cell carcinoma of the stomach. Br J Surg. 2004;91:1319-24.

9. Maehara Y, Sakaguchi Y, Moriguchi S, Orita H, Korenaga D, Kohnoe S, et al. Signet ring cell carcinoma of the stomach. Cancer. 1992;69:1645-50.

10. Kim JP, Kim SC, Yang HK. Prognostic significance of signet ring cell carcinoma of the stomach. Surg Oncol. 1994;3:221-7. 
11. Yokota T, Kunii Y, Teshima S, Yamada Y, Saito T, Kikuchi S, et al. Signet ring cell carcinoma of the stomach: a clinicopathological comparison with the other histological types. Tohoku J Exp Med. 1998;186:121-30.

12. Zhang M, Zhu G, Zhang H, Gao H, Xue Y. Clinicopathologic features of gastric carcinoma with signet ring cell histology. J Gastrointest Surg. 2010;14:601-6.

13. Watanabe H, Jass J, Sobin J. Histological typing of oesophageal and gastric tumors. In: WHO international histological classification of tumours. 2nd ed. Berlin: Springer; 1990.

14. Lauren P. The two histological main types of gastric carcinoma: diffuse and so-called intestinal-type carcinoma. An attempt at a histo-clinical classification. Acta Pathol Microbiol Scand. 1965;64:31-49.

15. Ming SC. Gastric carcinoma. A pathobiological classification. Cancer. 1977;39:2475-85.

16. Nakamura K, Sugano H, Takagi K. Carcinoma of the stomach in incipient phase: its histogenesis and histological appearances. Gann. 1968;59:251-8.

17. Japanese Research Society for Gastric Cancer. The general rules for the gastric cancer study in surgery. Jpn J Surg. 1973;3:61-71.

18. Ha TK, An JY, Youn HK, Noh JH, Sohn TS, Kim S. Indication for endoscopic mucosal resection in early signet ring cell gastric cancer. Ann Surg Oncol. 2008;15:508-13.

19. Huh C, Jung D, Kim J, Lee Y, Kim H, Yoon S, et al. Signet ring cell mixed histology may show more aggressive behavior than other histologies in early gastric cancer. J Surg Oncol. 2013;107:124-9.

20. Gronnier C, Messager M, Robb WB, Thiebot T, Louis D, Luc G, et al. Is the negative prognostic impact of signet ring cell histology maintained in early gastric adenocarcinoma? Surgery. 2013;154:1093-9.

21. Maehara Y, Hasuda S, Koga T, Tokunaga E, Kakeji Y, Sugimachi K. Postoperative outcome and sites of recurrence in patients following curative resection of gastric cancer. Br J Surg. 2000;87:353-7.

22. Kim DY, Park YK, Joo JK, Ryu SY, Kim YJ, Kim SK, et al. Clinicopathological characteristics of signet ring cell carcinoma of the stomach. ANZ J Surg. 2004;74:1060-4.

23. Taghavi S, Jayarajan S, Davey A, Willis A. Prognostic significance of signet ring gastric cancer. J Clin Oncol. 2012;30:3493-8.

24. Cunningham D, Allum W, Stenning S, Thompson J, Van de Velde CJH, Nicolson M, et al. Perioperative chemotherapy versus surgery alone for resectable gastroesophageal cancer. N Engl J Med. 2006;355:11-20.

25. Ychou M, Boige V, Pignon J-P, Conroy T, Bouché O, Lebreton $\mathrm{G}$, et al. Perioperative chemotherapy compared with surgery alone for resectable gastroesophageal adenocarcinoma: an FNCLCC and FFCD multicenter phase III trial. J Clin Oncol. 2011;29:1715-21.

26. Macdonald JS, Smalley SR, Benedetti J, Hundahl SA, Estes NC, Stemmermann GN, et al. Chemoradiotherapy after surgery compared with surgery alone for adenocarcinoma of the stomach or gastroesophageal junction. N Engl J Med Mass Med Soc. 2001;345:725-30.

27. Société Nationale Française de Gastroentérologie. Thésaurus National de Cancérologie Digestive; 2011. p. 1-26. http://www. snfge.com/data/ModuleDocument/publication/5/pdf/TNCD-cha pitre-2.pdf. Accessed 18 Nov 2015.

28. Japanese Research Society for Gastric Cancer. The general rules for the gastric cancer study in surgery and pathology_ part II. Jpn J Surg. 1981;11:127-39.

29. Sobin L, Gospodarowicz M, Wittekind C. TNM classification of malignant tumours. 7th ed. New York: Wiley-Blac; 2009.
30. Dindo D, Demartines N, Clavien P-A. Classification of surgical complications. Ann Surg. 2004;240:205-13.

31. De Angelis R, Sant M, Coleman MP, Francisci S, Baili P, Pierannunzio D, et al. Cancer survival in Europe 1999-2007 by country and age: results of EUROCARE-5-a population-based study. Lancet Oncol. 2014;15:23-34.

32. Hyung WJ, Noh SH, Lee JH, Huh JJ, Lah KH, Choi SH, et al. Early gastric carcinoma with signet ring. Cancer. 2002;94:78-83.

33. Jiang $\mathrm{H}$, Zhang $\mathrm{H}$, Tian $\mathrm{L}$, Zhang $\mathrm{X}$. The difference in clinicpathological features between signet ring cell carcinoma and gastric mucinous adenocarcinoma. Tumor. 2013;34:2625-31.

34. Kwon K-J, Shim K-N, Song E-M, Choi J-Y, Kim S-E, Jung H-K, et al. Clinicopathological characteristics and prognosis of signet ring cell carcinoma of the stomach. Gastric Cancer. 2014;17:43-53.

35. Otsuji E, Yamaguchi T, Sawai K, Takahashi T. Characterization of signet ring cell. S Surg Oncol. 1998;67:216-20.

36. Crew KD, Neugut AI. Epidemiology of gastric cancer. World J Gastroenterol. 2006;12:354-62.

37. Markar SR, Karthikesalingam A, Jackson D, Hanna GB. Longterm survival after gastrectomy for cancer in randomized, controlled oncological trials: comparison between West and East. Ann Surg Oncol. 2013;20:2328-38.

38. Bamboat ZM, Tang LH, Vinuela E, Kuk D, Gonen M, Shah MA, et al. Stage-stratified prognosis of signet ring cell histology in patients undergoing curative resection for gastric adenocarcinoma. Ann Surg Oncol. 2014;21:1678-85.

39. Kim SH, Karpeh MS, Klimstra DS, Leung D, Brennan MF. Effect of microscopic resection line disease on gastric cancer survival. J Gastrointest Surg. 1999;3:24-33.

40. Songun I, Bonenkamp JJ, Hermans J, van Krieken JH, van de Velde CJ. Prognostic value of resection-line involvement in patients undergoing curative resections for gastric cancer. Eur $\mathrm{J}$ Cancer. 1996;32A:433-7.

41. Kakeji Y, Maehara Y, Tomoda M, Kabashima A, Ohmori M, Oda $\mathrm{S}$, et al. Long-term survival of patients with stage IV gastric carcinoma. Cancer. 1998;82:2307-11.

42. Songun I, Putter H. Kranenbarg EM-K, Sasako M, van de Velde CJH. Surgical treatment of gastric cancer: 15-year follow-up results of the randomised nationwide Dutch D1D2 trial. Lancet Oncol. 2010;11:439-49.

43. Hartgrink HH, Jansen EPM, van Grieken NCT, van de Velde CJH. Gastric cancer. Lancet. 2009;374:477-90.

44. Edwards P, Blackshaw GRJC, Lewis WG, Barry JD, Allison MC, Jones DRB. Prospective comparison of D1 vs modified D2 gastrectomy for carcinoma. Br J Cancer. 2004;90:1888-92.

45. Mariani L, Miceli R, Lusa L, Di Bartolomeo M, Bozzetti F. A modified prognostic score for patients with curatively resected gastric cancer. Tumori. 2005;91:221-6.

46. Kattan MW, Karpeh MS, Mazumdar M, Brennan MF. Postoperative nomogram for disease-specific survival after an R0 resection for gastric carcinoma. J Clin Oncol. 2003;21:3647-50.

47. Kruizenga $\mathrm{H}$. Screening of nutritional status in The Netherlands. Clin Nutr. 2003;22:147-52.

48. Mann CD, Palser T, Briggs CD, Cameron I, Rees M, Buckles J, et al. A review of factors predicting perioperative death and early outcome in hepatopancreaticobiliary cancer surgery. HPB (Oxford). 2010;12:380-8.

49. Correia MI, Campos AC. Prevalence of hospital malnutrition in Latin America: the multicenter ELAN study. Nutrition. 2003;19:823-5.

50. Panis Y, Maggiori L, Caranhac G, Bretagnol F, Vicaut E. Mortality after colorectal cancer surgery: a French survey of more than 84,000 patients. Ann Surg. 2011;254:738-43 (discussion 743-4). 
51. Voron T, Tselikas L, Pietrasz D, Pigneur F, Laurent A, Compagnon $\mathrm{P}$, et al. Sarcopenia impacts on short- and long-term results of hepatectomy for hepatocellular carcinoma. Ann Surg. 2014;00:1-11.

52. Diaz-Nieto R, Orti-Rodríguez R, Winslet M. Post-surgical chemotherapy versus surgery alone for resectable gastric cancer. Cochrane Database Syst Rev. 2013;9:CD008415.

53. Paoletti X, Oba K, Burzykowski T, Michiels S, Ohashi Y, Pignon J, et al. Benefit of adjuvant chemotherapy for resectable gastric cancer. JAMA. 2010;303:1729-37.

54. Bang Y-J, Kim Y-W, Yang H-K, Chung HC, Park Y-K, Lee KH, et al. Adjuvant capecitabine and oxaliplatin for gastric cancer after D2 gastrectomy (CLASSIC): a phase 3 open-label, randomised controlled trial. Lancet. 2012;379:315-21.

55. Noh SH, Park SR, Yang H-K, Chung HC, Chung I-J, Lee KH, et al. Adjuvant capecitabine and oxaliplatin (Xelox) for gastric cancer after $\mathrm{d} 2$ gastrectomy: final results from the classic trial. Ann Oncol. 2013;24:iv14-iv14.

56. Piessen G, Messager M, Lefevre JH, Goéré D, Mabrut J-Y, Meunier B, et al. Signet ring cell adenocarcinomas: different clinical-pathological characteristics of oesophageal and gastric locations. Eur J Surg Oncol. 2014;40:1746-55.

57. Piessen G, Messager M, Le Malicot K, Robb WB, Di Fiore F, Guilbert M, et al. Phase II/III multicentre randomised controlled trial evaluating a strategy of primary surgery and adjuvant chemotherapy versus peri-operative chemotherapy for resectable gastric signet ring cell adenocarcinomas-PRODIGE 19-FFCD1103-ADCI002. BMC Cancer. 2013;13:281.

58. Bass AJ, Thorsson V, Shmulevich I, Reynolds SM, Miller M, Bernard B, et al. Comprehensive molecular characterization of gastric adenocarcinoma. Nature. 2014;513:202-9. 